\title{
The Discovery, Isolation, and Classification of Various $\alpha$-Haemolytic Micrococci which Resemble Aerococci
}

\author{
By O. G. CLAUSEN* \\ Department of Bacteriology, National Institute of Public Health, Oslo, \\ and Department of Bacteriology, Institute of Pharmacy, \\ University of Oslo, Blindern, Norway
}

(Received 10 June 1963)

\begin{abstract}
SUMMARY
This work describes the identification and classification of a hitherto unknown group of $\alpha$-haemolytic micrococci isolated from bottles containing dregs of fluid medicaments. The majority of the strains were both catalasepositive and nitratase-positive. In view of several similarities between these bacteria and the aerococci described by Shaw, Stitt \& Cowan (1951), and later by Williams, Hirch \& Cowan (1953), it is proposed that both groups should be incorporated in a new bacterial family, Aerococcaceae, despite the fact that the aerococci are catalase-negative and nitratasenegative. The suggestion that a new family should be established is prompted by the many dissimilarities between both the aforementioned groups and the representatives of the families to which they are closest according to the Bergey system. The new family ought to include one genus, Aerococcus, and two species, one of which, $A$. viridans, should comprise catalase-negative and nitratase-negative strains, and the other, $A$. catalasicus, strains which are obligate catalase-positive and may also be nitratase-positive.
\end{abstract}

\section{INTRODUCTION}

In the course of investigations made into the microbial flora found in the dregs of fluid medicaments in bottles handed in at three Oslo pharmacies in exchange for new medicines, I isolated $\alpha$-haemolytic micrococcus strains which, in their haemolytic, cultural and morphological properties, appear to be akin to the $\alpha$-haemolytic micrococci described by Shaw et al. (1951). It was proposed by Williams et al. (1953) that these bacteria, which are generally present in air and dust, should form a new genus, Aerococcus, with one species, $A$. viridans. Williams et al. thought that the genus Aerococcus was more closely related to the streptococci than to the micrococci, and that it should be placed in the same family as the streptococci. They referred to the similarity between aerococci and pediococci, but contended that the difference between these two groups was so marked that they should not be put in the same genus.

Deibel \& Niven (1960) found Aerococcus viridans to be identical, or very similar, to Gaffkya homari and proposed that both these micro-organisms should be included in a single species in the genus Pediococcus, since there are several characteristics common to these two species and the pediococci.

* Present address : Department of Bacteriology, Institute of Pharmacy, University of Oslo, Blindern, Norway.

Vol. 34, No. 3 was issued 25 May 1964 
Tjeltveit \& Clausen (1964) have recently shown inter alia that the strains of $\alpha$-haemolytic micrococci and a strain of Aerococcus viridans are homofermentative and produce lactic acid when a sufficient number of active bacterial cells are present during conversion of the glucose. The specific rotation of the lactic acid formed was not investigated.

\section{Cultural and morphological characteristics of the $\alpha$-haemolytic micrococcus strains}

Because the growth of these bacterial strains on solid media, such as ordinary agar and blood agar medium, resembles that of enterococci, they were at first considered to be $\alpha$-haemolytic species of Streptococcus faecalis. This assumption was borne out by their capacity for growth on $40 \%$ ox bile blood agar, in $6.5 \%$ sodium chloride beef-infusion peptone phosphate broth, and in the same broth with a normal content of sodium chloride $(0 \cdot 3 \%)$ but with a $\mathrm{pH}$ value of $\mathbf{9 \cdot 6}$. However, microscopic examination of ordinary broth cultures failed to reveal any true chain formation. The cocci were comparatively large, being approximately 1-2 $\mu$ in diameter, spherical or slightly irregular in shape, though not elongated; they occurred singly, in pairs, and in micrococcus-like formations. They were Gram-positive. Eleven culturally similar $\alpha$-haemolytic micrococcus strains were isolated from the medicine bottles and these strains were subjected to detailed study.

The $\alpha$-haemolytic strains develop at $22^{\circ}, 30^{\circ}$, and $37^{\circ}$; growth is poorest at $22^{\circ}$, best at $37^{\circ}$. On $5 \%$ citrated horse blood agar the size of the colonies ranges from 0.5 to $2 \mathrm{~mm}$. diam. after $18-24 \mathrm{hr}$ of incubation at $37^{\circ}$. They are convex in shape and vary in colour from grey to white. On one occasion the colonies were clear, transparent, and formed 'craters' when they aged, as do pneumococcus colonies. The $\alpha$-haemolytic micrococci formed colonies with green zones on 'chocolate' agar. Aerobic cultivation for $24 \mathrm{hr}$ at $37^{\circ}$ in beef-infusion peptone phosphate broth and in the same broth with $1 \%$ glucose resulted in sparse growth and relatively meagre sediment. When grown in broth with a petroleum jelly seal, all strains showed slighter growth with the formation of a little sediment after $24 \mathrm{hr}$ incubation at $37^{\circ}$ than when cultured aerobically. All strains grew well in modified HS-medium with $10 \%$ normal horse serum (Clausen, 1956), but the best growth occurred in the upper third of the medium. When a comparison was carried out using the type strain Aerococcus viridans NCTC 8251, it was found that this-compared with the eleven $\alpha$-haemolytic micrococcus strains-produced relatively weaker growth and a granular sediment in the aforementioned media.

The $\alpha$-haemolytic micrococci were examined according to the methods described below.

\section{METHODS}

Formulae are not given for media the composition of which must be assumed to be generally known. Unless otherwise stated, incubation was carried out at $37^{\circ}$. All cultures were incubated aerobically.

Optimum temperature for growth. Blood agar plates were prepared by addition of $5 \%$ citrated horse blood to a medium consisting of $1 \%$ peptone (Danish, Orthana Bacteriological Brand), $0.3 \% \mathrm{NaCl}, 0.2 \% \mathrm{Na}_{2} \mathrm{HPO}_{4}$, and $1.8 \%$ agar (Japanese, quality Kobe $\mathrm{I})$ in aqueous beef-infusion $(\mathrm{pH}=\mathbf{7 \cdot 4})$. Plates were poured to a 
constant depth, about $4 \mathrm{~mm}$. Each individual strain was subcultured to three blood agar plates; one was incubated at $22^{\circ}$, the others at $30^{\circ}$, and $37^{\circ}$. Growth was recorded after 24 and $48 \mathrm{hr}$.

Morphology. Unstained wet preparations of $24 \mathrm{hr}$ cultures of beef-infusion peptone phosphate broth with and without $1 \%$ glucose were examined. Grampreparations of the broth and blood agar cultures were examined.

Haemolysis was tested on $5 \%$ citrated horse blood agar after 24 and $48 \mathrm{hr}$ incubation.

Ox bile resistance was studied by inoculation on to $40 \%$ ox bile blood agar (40\% autoclaved ox bile, $8 \%$ defibrinated horse blood, and $\mathbf{5 2} \%$ agar medium with $2 \cdot 6 \%$ agar, quality Kobe I) and incubation for $20 \mathrm{hr}$.

Tellurite resistance was investigated by inoculating the strains on to McLeod's blood agar containing $0.04 \%$ potassium tellurite. Growth or lack of growth was recorded after $20 \mathrm{hr}$ incubation.

Thermoresistance was tested by heating a $20 \mathrm{hr}$ beef-infusion peptone phosphate broth culture at $60^{\circ}$ (in a water bath) for $30 \mathrm{~min}$., cooling, and subculturing to new broth and blood agar. The media were incubated for $48 \mathrm{hr}$ before the results were recorded. Each broth culture to be tested was drawn sufficiently far up a Pasteur pipette to enable the ends of the pipette to be sealed without heating the cultures. The pipette was then plunged so deeply into a water bath at $60^{\circ}$ that the entire section moistened with culture was submerged.

Growth tests were carried out in beef-infusion peptone phosphate broth with $6.5 \%$ $\mathrm{NaCl}$ or with a $\mathrm{pH}$ of $9 \cdot 6$; incubation period, $72 \mathrm{hr}$.

Methylene-blue reductase was tested in milk culture to which had been added $0.1 \%$ methylene blue. The reduction or lack of reduction was recorded after 20 and $48 \mathrm{hr}$ and finally after 5 days' incubation.

Reduction prior to coagulation of litmus milk was observed after 12 and $24 \mathrm{hr}$, and daily for 5 days.

Utilization and acid formation of certain sugars, alcohols and glycosides. $0.5 \%$ (aesculin $0.2 \%$ ) of the following sugars, etc., were added to peptone water $+5 \%$ normal horse serum $+1 \%$ Andrade's indicator: lactose, glucose, maltose, sucrose, raffinose, galactose, xylose, mannitol, dulcitol, glycerol, starch, dextrin, salicin, aesculin. Incubation period: 14 days.

Proteolytic activity: ability to liquefy gelatin was tested in stab cultures incubated at $22^{\circ}$ for 30 days.

The ability to liquefy inspissated ox serum was determined by incubation at $\mathbf{2 2}^{\circ}$ for up to 14 days.

Formation of catalase. $10 \% \mathrm{H}_{2} \mathrm{O}_{2}$ was added to $24 \mathrm{hr}$ agar slant cultures and observed for up to $5 \mathrm{~min}$. to determine whether gas was formed. Control tests were performed on non-inoculated agar slant media after $24 \mathrm{hr}$ incubation.

Formation of nitratase. Four-day cultures in nitrate broth were tested by adding Griess-Ilosvay reagent. Negative tests were checked by adding powdered zinc to prove that there was nitrate left in the culture medium. A surplus of nitrite in a culture can 'conceal' a positive reaction by decolorizing the red stain; for this reason the test was performed daily for up to 4 days (Shaw et al. 1951).

Formation of plasmacoagulase. Tests for this enzyme were performed by mixing equal parts of $24 \mathrm{hr}$ broth culture and a $1 / 10$ dilution of citrated human plasma in 
sterile saline solution, followed by incubation in a water bath at $37^{\circ}$ for $4 \mathrm{hr}$ and storage overnight at room temperature.

Formation of $\mathrm{H}_{2} \mathrm{~S}$. Stab cultures in lead acetate agar were incubated for 14 days.

Hydrolysis of arginin in broth accompanied by formation of $\mathrm{NH}_{3}$ was demonstrated by mixing equal parts of Nessler's reagent and $48 \mathrm{hr}$ arginine-containing broth culture.

Hydrolysis of sodium hippurate ( $1 \%$ ) in broth into sodium benzoate after 5 days' cultivation was determined by means of $12 \% \mathrm{FeCl}_{3}$ solution with $0 \cdot 2 \%$ concentrated HCl (Roemer, 1948).

Hydrolysis of urea. Christensen (1946) urea medium with indicator was used to demonstrate formation of $\mathrm{NH}_{3}$ by urease activity. Incubation period: 14 days.

Methyl red $(M R)$ and Voges-Proskauer (VP) tests were carried out with the following incubation periods and temperatures: MR test: 4,5 and 7 days at $30^{\circ}$. VP test: 3 and 4 days at $30^{\circ}$.

Determination of final $\mathrm{pH}$ in $1 \%$ glucose beef-infusion peptone phosphate broth $(\mathrm{pH}=\mathbf{7 \cdot 4})$ after 14 days. The $\mathrm{pH}$ was measured with a Beckman $\mathrm{pH}$ meter.

The following bacteria were used in certain tests as reference species: Aerococcus viridans NCTC 8251, Pediococcus cerevisiae NCTC 8066 and $P$. acidilactici NCIB 6990.

\section{RESULTS}

Most of the results of these investigations are given in Table 1. Comments on the results not tabulated are given below.

The test for tellurite resistance gave varying results, as one or two of the strains were tellurite-resistant, but the majority were not, or showed only traces of growth on tellurite medium. This test would appear to be of no significance in classifying these bacteria.

Growth in broth with 6.5\% $\mathrm{NaCl}$ was investigated with a positive result on all micrococcus strains as well as on Aerococcus viridans.

The test for hydrolysis of sodium hippurate gave positive results in the case of eight of the eleven strains examined, and two showed traces of hydrolysis. The test was not performed on aerococci.

In tests not recorded in the tables, the $\alpha$-haemolytic micrococcus strains did not form soluble haemolysin, they were non-pathogenic when injected intraperitoneally into white mice, and did not precipitate with streptococcus antisera of group D (Clausen, 1961).

The $\alpha$-haemolytic micrococci proved biochemically different from Aerococcus viridans in the following ways. (The biochemical properties of the aerococcus strains were determined by Williams et al. 1953, and Shaw et al. 1951).

(1) Reduction prior to coagulation of litmus milk. Five of eleven strains of $\alpha$ haemolytic micrococci reduced litmus in milk prior to coagulation, whereas none of 29 aerococcus strains did so.

(2) Acid production from raffinose. All $\alpha$-haemolytic micrococci utilized this carbohydrate, whereas only four of twelve aerococci did so.

(3) Acid production from mannitol. Only one of eleven $\alpha$-haemolytic micrococcus strains utilized this alcohol, whereas five out of twelve aerococci are reported to have done so. 
(4) Liquefaction of inspissated ox serum. Nine out of eleven $\alpha$-haemolytic micrococcus strains liquefied inspissated ox serum, whereas none of 29 aerococcus strains did so.

(5) Formation of catalase. Eight out of eleven $\alpha$-haemolytic micrococcus strains were catalase-positive, the majority being relatively strong formers of catalase.

Table 1. Cultural and biochemical properties of a group of $\alpha$-haemolytic micrococci compared with various strains of Aerococcus viridans

+ denotes positive reaction: 5 or more positive strains out of 11 or 12 tested. - denotes negative reaction: up to 4 positive strains out of 11 or 12 tested.

\begin{tabular}{|c|c|c|c|c|}
\hline & $\begin{array}{c}\alpha \text {-Haemolytic } \\
\text { micrococci }\end{array}$ & $\begin{array}{l}\text { No. positive } \\
\text { out of } 11 \\
\text { strains tested }\end{array}$ & A. viridans & $\begin{array}{l}\text { No. positive } \\
\text { out of } 12 \\
\text { strains tested* }\end{array}$ \\
\hline $\begin{array}{l}\text { Optimum temperature for } \\
\text { growth } 37^{\circ}\end{array}$ & + & 11 & + & $66 \% \dagger$ \\
\hline$\alpha$-Haemolytic on blood agar & + & $11+$ & + & 12 \\
\hline Growth on $40 \%$ ox bile agar & + & 11 & + & 12 \\
\hline Resist $60^{\circ}$ for $30 \mathrm{~min}$. & + & 11 & + & 12 \\
\hline Growth in broth at pH 9.6 & + & 11 & + & 11 \\
\hline $\begin{array}{l}\text { Reduction of } 0 \cdot 1 \% \text { methylene } \\
\text { blue in milk }\end{array}$ & - & $1(2) \S$ & - & $\mathbf{0}$ \\
\hline $\begin{array}{l}\text { Reduction prior to coagulation } \\
\text { of litmus milk }\end{array}$ & + & $\mathbf{5} \|$ & - & $0 \dagger$ \\
\hline \multicolumn{5}{|l|}{ Utilization of } \\
\hline Lactose & + & 9 & + & 10 \\
\hline Glucose & + & 11 & + & 12 \\
\hline Maltose & + & 11 & + & 12 \\
\hline Saccharose & + & 11 & + & 12 \\
\hline Raffinose & + & 11 & - & 4 \\
\hline Galactose & + & 11 & + & $97 \% \dagger$ \\
\hline Xylose & - & 0 & + & $41 \% \dagger$ \\
\hline Mannitol & - & $\mathbf{I}$ & + & $\mathbf{5}$ \\
\hline Dulcitol & - & $\mathbf{0}$ & - & $0 \dagger$ \\
\hline Glycerol & + & $\mathbf{9}$ & + & $97 \% \dagger$ \\
\hline Starch & - & 4 & - & 09 \\
\hline Dextrin & - & 4 & - & $38 \% \dagger$ \\
\hline Salicin & + & 8 & + & $83 \% \dagger$ \\
\hline Aesculin & + & 8 & + & $12 \pi$ \\
\hline Gelatin liquefaction & - & 0 & - & 0 \\
\hline $\begin{array}{l}\text { Liquefaction of inspissated ox } \\
\text { serum }\end{array}$ & + & $\mathbf{9}$ & - & $0 \dagger$ \\
\hline Catalase formation & + & 8 & - & $\mathbf{0}$ \\
\hline Nitratase formation & + & $6(7) \S$ & - & $0 \dagger$ \\
\hline Plasma coagulase formation & - & $\mathbf{0}$ & - & $\mathbf{0}$ \\
\hline $\mathbf{H}_{2} \mathrm{~S}$ formation & - & $\mathbf{0}$ & - & 0 \\
\hline Hydrolysis of arginine & - & $\mathbf{0}$ & - & $\mathbf{0}$ \\
\hline Hydrolysis of urea & - & 0 & - & $\mathbf{0}$ \\
\hline MR positive & - & $0^{* *}$ & + & $93 \% \dagger$ \\
\hline VP positive & - & $\mathbf{0}$ & - & 0 \\
\hline Final pH & $5 \cdot 2-5 \cdot 6$ & 11 & $5 \cdot 5-5 \cdot 8$ & 12 \\
\hline \multicolumn{5}{|c|}{$\begin{array}{l}\text { * Most of these data are from Williams et al. }(\mathbf{1 9 5 3}) \text {. } \\
\dagger \text { According to Shaw } \text { et al. }(\mathbf{1 9 5 1 )} \text { : the percentage positive out of } 29 \text { strains tested. } \\
\ddagger \text { From distinctly } \alpha \text {-haemolytic to faintly } \alpha^{\prime} \text {-haemolytic. } \\
\S \text { The figures in parentheses include also strains which show weak positive reactions. } \\
\text { il Slow reduction. } \\
\text { T Examined in solid media. }\end{array}$} \\
\hline
\end{tabular}


Only one of the catalase-forming strains may be described as weakly positive, and one as a moderate to weak catalase former. These two strains did not reduce nitrate to nitrite. The aerococci are reported not to form catalase.

(6) Formation of nitrite from nitrate. Six (+1 uncertain) out of the eleven $\alpha$-haemolytic micrococcus strains formed nitrite from nitrate, whereas none of 29 aerococcus strains did so.

\section{Differences between the $\alpha$-haemolytic micrococci, Aerococcus viridans and the pediococci}

The $\alpha$-haemolytic micrococci and Aerococcus viridans have been compared with $\boldsymbol{P e d i o c o c c u s ~ c e r e v i s i a e ~ a n d ~} \boldsymbol{P}$. acidilactici with the aid of various growth and resistance tests, which gave the following results : the $\alpha$-haemolytic micrococci and $A$. viridans did not grow at $37^{\circ}$ (14 days) or $25^{\circ}$ (30 days) in the pediococcal media, unhopped wort, yeast-water with autolysed yeast, or Bettge \& Heller's beer with starch (Jörgensen, 1956a), the last two media containing $2.5 \%(\mathrm{v} / \mathrm{v})$ alcohol, whereas both pediococci grew well in all three media. The $\alpha$-haemolytic micrococci and the aerococcus were also MR and VP negative, whereas the pediococci were highly MR positive. On the other hand, only $\boldsymbol{P}$. cerevisiae (not $\boldsymbol{P}$. acidilactici) produced acetyl methyl carbinol. Moreover, the $\alpha$-haemolytic micrococci and the aerococcus grew in $6.5 \% \mathrm{NaCl}$ broth and in broth with a pH of 9.6. Neither of the pediococci developed in these two media; this applied both when incubated at $37^{\circ}$ for 5 days and when incubated at $25^{\circ}$ for 15 days. Furthermore, the pediococci were not $\alpha$-haemolytic when grown on blood agar $(P$. cerevisiae may at the most produce a very weak greening reaction), they have a much lower final $\mathrm{pH}$ value (cf. the strong MR positive reaction) than the $\alpha$-haemolytic micrococci and the aerococci (Williams et al. 1953), and they form more typical microaerophilic colonies when grown under aerobic conditions on ordinary agar medium and blood agar. One species, $P$. cerevisiae, had a growth-optimum at a comparatively low temperature between 18 and $25^{\circ}$ (Jörgensen, 1956b).

\section{DISCUSSION}

While it has been possible to demonstrate appreciable differences in the biochemical properties of the $\alpha$-haemolytic micrococci investigated and the aerococci described by Shaw et al. (1951) and Williams et al. (1953), it has also been shown that there is a great similarity between them, culturally and morphologically, and in regard to many biochemical criteria, especially to the tolerance tests: growth in broth with a $\mathrm{pH}$ of $\mathbf{9 \cdot 6}$, growth on $40 \%$ ox bile blood agar, and resistance to $60^{\circ}$ for $30 \mathrm{~min}$. On the other hand the aerococci, unlike the $\alpha$-haemolytic micrococci, are reported to be negative with regard to several other properties.

The formation of catalase is probably the most important difference between the $\alpha$-haemolytic micrococci and the aerococci, and eight out of eleven of the former strains are catalase formers, whereas the aerococci are reported to be catalase negative. Aerococcus viridans (NCTC 8251) showed a negative or at the most a slight trace of a positive reaction. As the formation of catalase is a property characteristic of micrococci, but invariably absent from streptococci, a distinction should be made between catalase-positive and catalase-negative strains of the $\alpha$-haemolytic micro- 
cocci. The three catalase-negative strains investigated differed very little in other biochemical properties from the rest of the strains. However, they were nitritenegative, as is $A$. viridans. A minor difference between them and the one aerococcus strain with which they have been compared ( $A$. viridans NCTC 8251) was their formation of denser white colonies on blood agar; the $\alpha$-haemolysis was weaker in the case of two of the strains, and they also appeared by microscopic examination to be somewhat larger in fluid medium. Moreover, $A$. viridans, unlike the $\alpha$-haemolytic micrococcus strains, formed granular sediment in broth cultures.

Viewed in the light of these properties, the micrococcus strains investigated may be said to be closely akin to the aerococci, but the catalase-positive and nitratasepositive strains were not identical with the aerococcus species Aerococcus viridans proposed by Williams et al. (1953).

All the $\alpha$-haemolytic micrococci investigated and also the Aerococcus viridans strain examined were homofermentative lactic-acid formers (Tjeltveit \& Clausen, 1964), but a reference staphylococcus strain, Staphylococcus epidermidis, was also found to have the same property. It may be mentioned that Orla-Jensen (1919) found that $\boldsymbol{S}$. aureus formed optically inactive or laevorotatory, and Micrococcus caseolyticus dextrorotatory lactic acid from $\mathbf{D}$-glucose, so that the fermentative powers of the strains cannot be regarded as decisive for their classification, either. Morphologically the bacterial strains were not streptococci, and it is obvious that the aerococci and the other catalase-negative micrococci lack the conclusive criteria for classification within the enterococcus group, the only group they really can be compared with in the family Lactobacillaceae. The catalase-positive strains cannot be classified in any genus under Tribe I, Streptococceae, Bergey's Manual (1957) as all the genera within the Tribe are catalase-negative. From these comparative studies of the $\alpha$-haemolytic micrococci and of $A$. viridans on the one hand and of the pediococci on the other, it was found that the difference between the two groups is so great that there is no justification for including the first group in the genus Pediococcus. Nor, without further study, can it be decided whether Gaffkya homari, which is of marine origin, is identical with the air and dust bacterium A. viridans, as proposed by Deibel \& Niven (1960).

The $\alpha$-haemolytic micrococci can be classified neither in the genus Leuconostoc, which includes only heterofermentative species, nor in the genus Peptostreptococcus, which includes only anaerobes. These $\alpha$-haemolytic micrococci differ, however, to such an extent from the representatives of the genera in the family Micrococcaceae, that they do not appear to belong here either. The genera of this family do not include $\alpha$-haemolytic species. Deibel \& Niven (1960) found that Gaffkya homari produced a strong greening reaction on sheep blood agar, whereas Bergey's Manual (1957) describes this bacterium as $\beta$-haemolytic on human blood agar. The only genus which might be considered, viz. Micrococcus, comprises only species which differ markedly from the bacteria being considered.

It is proposed to establish a new family in the Order Eubacteriales, because of the great specificity of the bacterial group in question. It is now suggested that the species Aerococcus viridans, which is catalase-negative, should be supplemented by a new, catalase-positive species. As the generic name of Aerococcus has formerly been used, this name should be retained, and the same designation should be incorporated in the new family name. 
In the light of the foregoing data it is proposed that the following family, genus, and species names should be given to the bacteria:

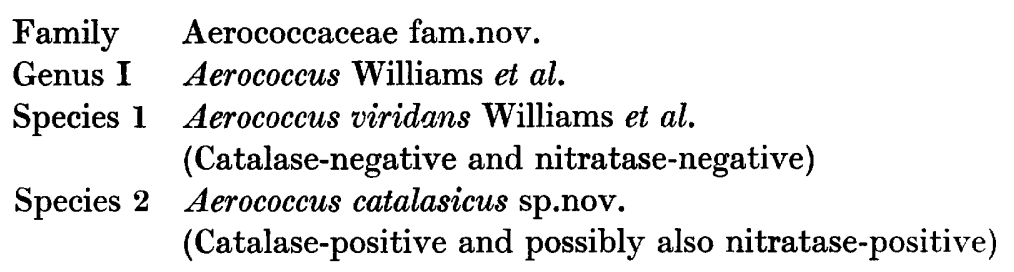

Further details of the family, generic, and specific properties will be evident from the foregoing.

I wish to express my sincerest thanks to S. Dick Henriksen, M.D., Professor at the Medical Institute of Bacteriology at the University of Oslo, who was my chief at the time most of this work was performed, and who helped me to solve many of the problems I encountered in carrying out my investigations. I should also like to record my gratitude to R. Saxholm, M.D., Senior Medical Officer of the Bacteriological Department at the National Institute of Public Health, Oslo, for his generous support in connexion with the later investigations that form part of this work. Finally, particular thanks are due to Mrs Grethe Barbo, laboratory assistant, who rendered me valuable aid in performing many important experiments. I am indebted to S. Rasch, M.Sc., Ringnes Brewery, Oslo, for the pediococcal media he so kindly procured for me.

\section{REFERENCES}

Bergey's Manual of Determinative Bacteriology. (1957). 7th edn. Ed. by R. S. Breed, E. G. D. Murray \& N. R. Smith. London: Baillière, Tindall \& Cox.

Christensen, W. B. (1946). Urea decomposition as a means of differentiating Proteus and paracolon cultures from each other and from Salmonella and Shigella types. J. Bact. $52,461$.

Clausen, O. G. (1956). Modified hydrosulphite medium (Bonnel) as a new aerobic and anaerobic control medium for sterility tests. Acta path. microbiol. Scand. 38, 107.

Clausen, O. G. (1961). Mutation of a beta-haemolytic streptococcus strain of group 0 . J. Path. Bact. 82, 212.

Deibel, R. H. \& Niven, C. F., Jr. (1960). Comparative study of Gaffkya homari, Aerococcus viridans, tetrad-forming cocci from meat curing brines, and the genus Pediococcus. J. Bact. 79, 175.

Jørgensen, A. (1956). Microorganismen der Gärungsindustrie. 7th ed. Rewritten by A. Hansen, p. 525. Nürnberg: Verlag Hans Carl.

Orla-Jensen, S. (1919). The Lactic Acid Bacteria. Copenhagen: Ejnar Munksgaard.

Roemer, G. B. (1948). Untersuchungen über die biochemischen Eigenschaften menschenpathogener Streptokokken und ihre Beziehungen zur serologischen Gruppenzugehörigkeit. Zbl. Bakt. (1. Abt. Orig.), 152, 458.

Shaw, C., Stitt, J. M. \& Cowan, S. T. (1951). Staphylococci and their classification. J. gen. Microbiol. 5, 1010.

TJeltveit, O. J. \& Clausen, O. G. (1964). Investigation into the ability of certain $\alpha$-haemolytic micrococci to form lactic acid from D-glucose. J. gen. Microbiol. 34, 555.

Williams, R. E. O., Hirch, A. \& Cowan, S. T. (1953). Aerococcus, a new bacterial genus. J. gen. Microbiol. 8, 475. 